\title{
Deletion of Smooth Muscle Lethal Giant Larvae 1 Promotes Neointimal Hyperplasia in Mice
}

\author{
Ya Zhang ${ }^{1}$, Peidong Yuan ${ }^{1,2}$, Xiaoping $\mathrm{Ma}^{3}$, Qiming Deng ${ }^{1}$, Jiangang $\mathrm{Gao}^{4}$, Jianmin Yang ${ }^{1}$, \\ Tianran Zhang ${ }^{5 *}$, Cheng Zhang ${ }^{1 *}$ and Wencheng Zhang ${ }^{1,2 *}$ \\ ${ }^{1}$ The Key Laboratory of Cardiovascular Remodeling and Function Research, The State and Shandong Province Joint Key \\ Laboratory of Translational Cardiovascular Medicine, Department of Cardiology, Chinese Ministry of Education, Chinese National \\ Health Commission and Chinese Academy of Medical Sciences, Qilu Hospital, Cheeloo College of Medicine, Shandong \\ University, Jinan, China, ${ }^{2}$ Cardiovascular Disease Research Center of Shandong First Medical University, Central Hospital \\ Affiliated to Shandong First Medical University, Jinan, China, ${ }^{3}$ Department of Obstetrics and Gynecology, Liaocheng People's \\ Hospital, Liaocheng, China, ${ }^{4}$ School of Life Science and Key Laboratory of the Ministry of Education for Experimental Teratology, \\ Shandong University, Jinan, China, ${ }^{5}$ Department of Cardiology, The First Affiliated Hospital of Zhengzhou University, Zhengzhou, \\ China
}

OPEN ACCESS

Edited by:

Qilong Wang,

Tianjin University of Traditional Chinese Medicine, China

Reviewed by: Jinlong He,

Tianjin Medical University, China

Qiulun Lu,

Nanjing Medical University, China

*Correspondence:

Tianran Zhang

714136498@qq.com

Cheng Zhang

zhangc@sdu.edu.cn

Wencheng Zhang

zhangwencheng@sdu.edu.cn

Specialty section:

This article was submitted to Cardiovascular and Smooth Muscle Pharmacology,

a section of the journa

Frontiers in Pharmacology

Received: 13 December 2021 Accepted: 06 January 2022

Published: 24 January 2022

Citation:

Zhang Y, Yuan P, Ma X, Deng Q, Gao J, Yang J, Zhang $T$, Zhang $C$ and Zhang W (2022) Deletion of Smooth

Muscle Lethal Giant Larvae 1

Promotes Neointimal Hyperplasia

in Mice.

Front. Pharmacol. 13:834296. doi: 10.3389/fphar.2022.834296
Vascular smooth muscle cell (VSMC) proliferation and migration contribute to neointimal hyperplasia after injury, which causes vascular remodeling related to arteriosclerosis, hypertension, and restenosis. Lethal giant larvae 1 (LGL1) is a highly conserved protein and plays an important role in cell polarity and tumor suppression. However, whether LGL1 affects neointimal hyperplasia is still unknown. In this study, we used smooth muscle-specific LGL1 knockout (LGL1 ${ }^{\mathrm{SMKO}}$ ) mice generated by cross-breeding LGL1 $1^{\text {floxflox }}$ mice with $\alpha$ SMA-Cre mice. LGL1 expression was significantly decreased during both carotid artery ligation in vivo and PDGF-BB stimulation in vitro. LGL1 overexpression inhibited the proliferation and migration of VSMCs. Mechanistically, LGL1 could bind with signal transducer and activator of transcription 3 (STAT3) and promote its degradation via the proteasomal pathway. In the carotid artery ligation animal model, smooth muscle-specific deletion of LGL1 accelerated neointimal hyperplasia, which was attenuated by the STAT3 inhibitor SH-4-54. In conclusion, LGL1 may inhibit neointimal hyperplasia by repressing VSMC proliferation and migration via promoting STAT3 proteasomal degradation.

Keywords: LGL1, STAT3, neointimal hyperplasia, smooth muscle, proteasomal degradation

\section{INTRODUCTION}

Neointimal hyperplasia is a significant type of vascular remolding defined as the pathological accumulation of vascular smooth muscle cells (VSMCs) and extracellular matrix (ECM) in the intima. It is a process of excessive repair in the vascular wall caused by various activated cells and recycling substances responding to vessel injury (Zaman and Herath, 2008). Vascular injury inevitably occurs with various clinical procedures. Percutaneous coronary interventions such as balloon angioplasty and stents to treat ischemic coronary artery disease, vein grafts for coronary artery bypass graft surgery, and vascular access in hemodialysis can result in lumen re-narrowing and restenosis in a year after the operation (Schwartz et al., 1995; RoyChaudhury et al., 2001; Roy-Chaudhury et al., 2007; Harskamp et al., 2013; Byrne et al., 2017).

The behavior of VSMCs plays a vital role in neointimal hyperplasia. Gathering around the vessel lesion, activated inflammatory cells, and disturbed endothelial cells release a number of factors such as platelet-derived growth factor (PDGF) to stimulate the proliferation of VSMCs and subsequent 
migration from the media layer of the vessel to the intima (Dzau et al., 1991; Majesky et al., 1991; Nabel et al., 1993; Grant et al., 1994; Dzau et al., 2002). Previous studies have revealed that neointimal hyperplasia is regulated by many proteins including signal transducer and activator of transcription 3 (STAT3) (Dutzmann et al., 2015). When VSMCs are activated by cytokines or growth factors, STAT3 is phosphorylated and translocates into the nucleus to regulate the expression of target genes involved in proliferation and migration (Park et al., 2000). Earlier researchers found that blocking STAT3 by adenovirus-expressing domain-negative STAT3 or siRNA could inhibit VSMC proliferation and migration, thus decreasing neointimal formation in models of carotid balloon injury or jugular vein-carotid artery bypass (Shibata et al., 2003; Wang et al., 2007; Sun et al., 2012). Similarly, the administration of STAT3 inhibitor downregulated its activity and suppressed VSMC proliferation and migration in neointimal hyperplasia (Lim et al., 2007; Daniel et al., 2012). Although the role of STAT3 in neointimal hyperplasia is clear, the regulation of STAT3 expression and activity needs further exploration.

Lethal giant larvae (LGL) proteins are a group of highly conserved proteins first discovered in Drosophila (Grifoni et al., 2004). LGL1 and LGL2 are two homologs in mammals (Russ et al., 2012). LGL1 maintains cell polarity and acts as a tumor suppressor (Bilder et al., 2000; Kuphal et al., 2006; Tian and Deng, 2008; Lu et al., 2009). In our recent study, LGL1 could inhibit vascular calcification via high mobility group box 1 (Zhang et al., 2020). Nonetheless, the role of LGL1 in neointimal hyperplasia after the vascular injury has not been elucidated.

Here, we used smooth muscle-specific LGL1 knockout (LGL1 ${ }^{\mathrm{SMKO}}$ ) mice to explore the function of smooth-muscle LGL1 in neointimal hyperplasia. We found that LGL1 could inhibit neointimal hyperplasia after injury via STAT3.

\section{MATERIALS AND METHODS}

\section{Reagents}

Adenovirus-expressing LGL1 and its control green fluorescent protein (GFP) were purchased from Vigenebio (Maryland, United States). Recombinant human PDGF-BB was from Proteintech (Wuhan, China). 3-Methyladenine (3-MA), MG132 and SH-4-54 were from Selleck Chemicals (Shanghai, China). SH-4-54 could effectively inhibit the phosphorylation of STAT3. The IC50 of SH-4-54 to STAT3 is $300 \mathrm{nM} \mathrm{(Kd).}$ Chloroquine (CQ) was from MCE (Shanghai, China).

\section{Mice}

Smooth muscle-specific LGL1-knockout $\left(\mathrm{LGL1}^{\mathrm{SMKO}}\right)$ mice were generated by cross-breeding LGL1 ${ }^{\text {flox/flox }}$ mice (Klezovitch et al., 2004) with transgenic Cre mice controlled by $\alpha$-smooth muscle actin (a-SMA) promoter (Wu et al., 2007) as described (Zhang et al., 2020). Littermate LGL1 ${ }^{\text {flox/flox} / C r e-~ m i c e ~ w e r e ~ u s e d ~ a s ~}$ controls (CTR). All mice were bred at a constant temperature of $25^{\circ} \mathrm{C}$ and under a 12-hr-day/night light cycle. All animal experiments were performed with the protocols approved by the Animal Care and Use Committee of Shandong University.
Animal Model for Neointimal Hyperplasia

We used common carotid artery (CCA) ligation to induce neointimal hyperplasia as reported previously (Wu et al., 2019). Briefly, 8-weekold mice were anesthetized with an intraperitoneal injection of sodium pentobarbital $(40 \mathrm{mg} / \mathrm{kg})$. A $10-15-\mathrm{mm}$ median incision was made, and bilateral CCAs were carefully separated from veins and nerves. After exposing the left CCA, the ligation was performed below the bifurcation with 6-0 silk suture, above which are internal and external carotid arteries. The right CCA as a sham was processed as for the left CCA except for ligation. The neck incision was sutured, and animals were resuscitated in a warm and clean condition. After 3 weeks, mice were euthanized to collect tissues.

\section{Primary Culture of VSMCs}

Mice at 4-6 weeks old were euthanized with sodium pentobarbital $(40 \mathrm{mg} / \mathrm{kg})$. Aortas were isolated and placed in culture dishes containing phosphate buffered saline (PBS). After dissection of extravascular connective tissues and adventitia, VSMC-enriched tunica media was transferred into tubes with cell culture medium and then cut into about $1 \times 1-\mathrm{mm}^{3}$ pieces. The tissue suspension was smeared evenly on the bottom of the culture bottle, which was inverted in a humidified incubator at $37^{\circ} \mathrm{C}$ and $5 \% \mathrm{CO}_{2}$ for $2 \mathrm{~h}$ until small blocks adhered firmly to the surface. Adequate cell culture medium containing $15 \%$ fetal bovine serum, $100 \mu \mathrm{g} / \mathrm{ml}$ streptomycin and $100 \mathrm{U} / \mathrm{mL}$ penicillin was supplied, and bottles were turned over in the incubator to observe crawling cells 5-7 days later. When cell confluency reached about $80-90 \%$, cells were passaged and plated for further use.

\section{Western Blot Analysis}

The RIPA buffer (Solarbio. R0010) was used to extract proteins from cells and tissues. Proteins were fractionated by SDS-PAGE gel and transferred to PVDF membranes. After blocking with 5\% skim dried milk/TBST for $1 \mathrm{~h}$, membranes were incubated overnight at $4^{\circ} \mathrm{C}$ with primary antibodies, washed with TBST, incubated with corresponding secondary antibodies and observed by enhanced chemiluminescence (Pierce). The primary antibodies used were LGL1 monoclonal antibody (mAb) (CST, 12159s), GAPDH mAb (CST, 5174s), $\beta$-tubulin mAb (CST, 5568s), Cyclin D1 (CST, $55506 \mathrm{~s}$ ), proliferating cell nuclear antigen (PCNA) mAb (CST, 13110s), STAT3 mAb (CST, 9139s), and P-STAT3 (Y705) mAb (CST, 9145s). ImageJ software was used for analysis. All experiments were performed at least three times.

\section{Co-Immunoprecipitation}

VSMCs were lysed with lysis buffer (Beyotime, P0013) and incubated with IgG or anti-LGL1 antibody at $4^{\circ} \mathrm{C}$ overnight to form an antigen-antibody complex. Then protein A/G magnetic beads were added (MCE, HY-K0202). After washing and magnetic separation, the precipitation was dissolved with $1 \times$ SDS loading buffer for western blot analysis.

\section{Quantitative Real-Time Polymerase Chain Reaction}

Total RNA was extracted from VSMCs and tissues by using an RNAfast200 kit (Fastagen, 220011), then a PrimeScript RT 
reagent kit (Takara, RR0037A) was applied to reverse transcript total RNA to complementary DNA. PCR amplification was performed with the SYBR Premix Ex Taq (Takara, RR420A). The primers' sequences were as follows. LGL1: $5^{\prime}$-TACTGTGAT CAGCCCAAGACTG- $3^{\prime}$ and $5^{\prime}$ - GGAGGATCCCAAGATAGA GGAC- $3^{\prime}$. GAPDH: $5^{\prime}$ - GCACCGTCAAGGCTGAGAAC- $3^{\prime}$ and $5^{\prime}$-TGGTGAAGACGCCAGTGGA-3'. Cyclin D1: $5^{\prime}$-AGG CGGATGAGAACAAGCAG- $3^{\prime}$ and $5^{\prime}-$ AGAAAGTGCGTT GTGCGGTA- ${ }^{\prime}$. PCNA: 5'-TACAGCTTACTCTGCGCTCC- ${ }^{\prime}$ and $5^{\prime}$-TTTTGGACATGCTGGTGAGGT-3'. STAT3: $5^{\prime}$-AGG ACATCAGTGGCAAGACC- $3^{\prime}$ and $5^{\prime}$-CCTTGGGAATGT CGGGGTAG-3'.

\section{Cell Proliferation Assay}

Cell counting kit-8 (CCK-8) (Solarbio, CA1210) was used to assess cell proliferation. Briefly, VSMCs were seeded in 96-well plates at $5 \times 10^{3} /$ well. After being induced with PDGF-BB for $48 \mathrm{~h}$, the culture medium was replaced with $100 \mu \mathrm{L}$ fresh medium, and $10 \mu \mathrm{L}$ CCK- 8 reagent was added to wells. Then plates were kept out of light and continuously incubated at $37^{\circ} \mathrm{C}$ and $5 \% \mathrm{CO}_{2}$ for $1 \mathrm{~h}$ in the incubator. The absorbance was detected at $450 \mathrm{~nm}$ by using a microplate reader (Molecular Devices, SpectraMax Plus 384) and optical density (OD) was recorded.

\section{Wound Healing Assay}

The scratch wound healing assay in vitro was used to evaluate cell migration. VSMCs were seeded in 12 -well plates at $6 \times 10^{4} /$ well. When cell confluency reached about $70-80 \%$, a standard wound was made with a $200 \mu \mathrm{L}$ micropipette tip for each well. VSMCs were then incubated for another 18 or $24 \mathrm{~h}$. Images were captured under an inverted microscope (Nikon Instruments). Wound closure (\%), defined as a cell coverage area in the wound divided by the total wound area, was calculated to represent migrative ability.

\section{Hematoxylin and Eosin Staining}

Carotid arteries were excised carefully from CTR and LGL1 ${ }^{\text {SMKO }}$ mice, fixed with $4 \%$ paraformaldehyde for $24 \mathrm{~h}$ and embedded in paraffin. Tissues were cut in serial $5-\mu \mathrm{m}$ sections. After deparaffinization and rehydration, hematoxylin was used to stain the nucleus for $3 \mathrm{~min}$. Differentiation was processed in $1 \%$ hydrochloric acid alcohol for $5 \mathrm{~s}$. Then eosin was applied for cytoplasm and ECM staining for $2 \mathrm{~min}$. The excessive stain was washed, then tissue was dehydrated in gradient alcohol and transparentized in xylene. The slides were sealed by neutral gum, and images were captured under a microscope (Nikon Instruments).

\section{Immunohistochemistry}

After deparaffinization and rehydration, slides were immersed in antigen repair buffer (Proteintech, PR30002) and underwent a microwave thermal repair method for $20 \mathrm{~min}$. Endogenous peroxide was inactivated with $0.3 \% \mathrm{H}_{2} \mathrm{O}_{2}$ at $37^{\circ} \mathrm{C}$ for $10 \mathrm{~min}$ and non-specific antibody binding was blocked with $5 \%$ bovine serum albumin. The slides were incubated with primary antibodies at $4^{\circ} \mathrm{C}$ overnight. After three cycles of washing with PBS, sections were incubated with secondary antibodies at $37^{\circ} \mathrm{C}$ for $30 \mathrm{~min}$, then diaminobenzidine as a chromogen was dropped on sections for 2-5 min. The images were viewed under a microscope (Nikon Instruments).

\section{Statistical Analysis}

GraphPad Prism 9.0 (GraphPad Software, San Diego, CA) was used for all statistical analyses. All data are presented as mean \pm SEM. The normality assumption of the data distribution was assessed by the Kolmogorov-Smirnov test. For the normal distribution, a two-tailed Student unpaired $t$-test was used to compare two groups. Differences between multiple groups with one variable were analyzed by one-way ANOVA followed by Bonferroni's post-hoc test. $p<0.05$ was considered statistically significant.

\section{RESULTS}

\section{LGL1 Expression was Decreased During Vascular Injury}

To explore the relation between LGL1 level and vascular injury, we examined the expression of LGL1 in the mouse model of neointimal hyperplasia. The protein and mRNA levels of LGL1 were decreased in carotid arteries after ligation as compared with the sham group (Figures 1A,B). The reduced LGL1 expression was confirmed by immunohistochemistry (Figure 1C). Next, VSMCs were treated with PDGF-BB $(20 \mathrm{ng} / \mathrm{ml})$, a potent stimulator of VSMCs and a key mediator in vascular injury, for different times. LGL1 expression began to decrease after $12 \mathrm{~h}$ of stimulation (Figure 1D). Thus, the LGL1 level was related to vascular injury, which suggests that LGL1 may be involved in the development of neointimal hyperplasia.

\section{LGL1 Overexpression Inhibited the Proliferation and Migration of VSMCs}

To explore the role of LGL1 in vascular injury, VSMCs were infected with adenovirus-expressing GFP or LGL1, then treated with PDGFBB. PDGF-BB could increase the protein expression of Cyclin D1 and PCNA, markers of cell proliferation, which was inhibited by LGL1 overexpression (Figure 2A). Similarly, PDGF-BB-upregulated Cyclin D1 and PCNA mRNA levels were also attenuated by LGL1 overexpression (Figures 2B,C). Cell viability assay revealed PDGF-BB promoted VSMC proliferation, which was suppressed by LGL1 overexpression (Figure 2D). Furthermore, on wound healing assay, LGL1 inhibited VSMC migration (Figure 2E). Hence, LGL1 overexpression inhibited the proliferation and migration of VSMCs.

\section{LGL1 Deletion Aggravated the Proliferation and Migration of VSMCs}

To comprehensively confirm the function of LGL1 in VSMCs, we cultured primary VSMCs from control and LGL1 ${ }^{\mathrm{SMKO}}$ mice. PDGF-BB increased the protein expression of Cyclin D1 and PCNA, which was further upregulated by LGL1 deficiency (Figure 3A). The mRNA levels of Cyclin D1 and PCNA were further augmented by LGL1 deletion under PDGF-BB stimulation (Figures 3B,C). PDGF-BB-induced VSMC proliferation was enhanced by LGL1 deficiency (Figure 3D) 

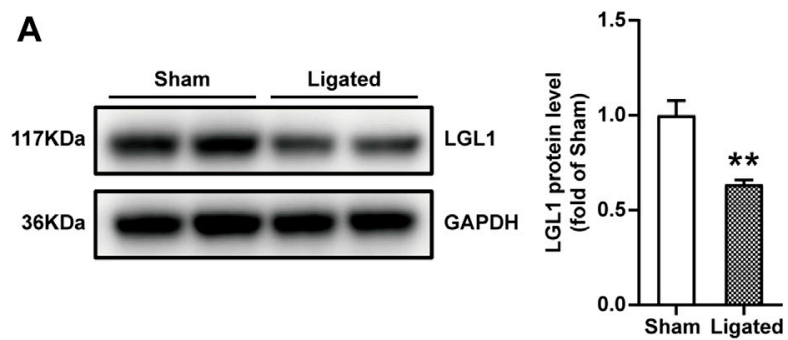

C
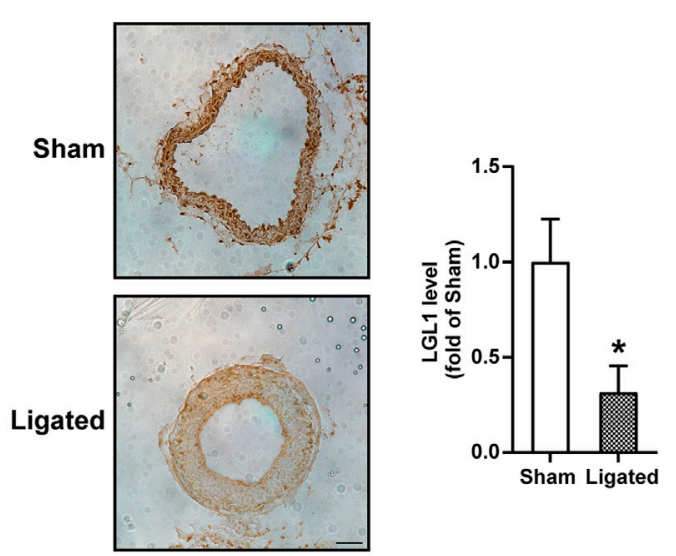

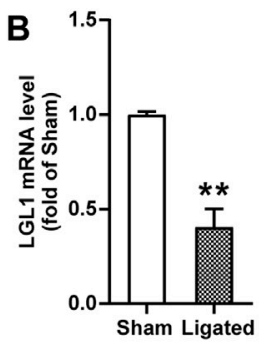

D

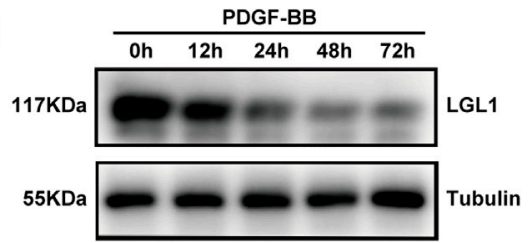

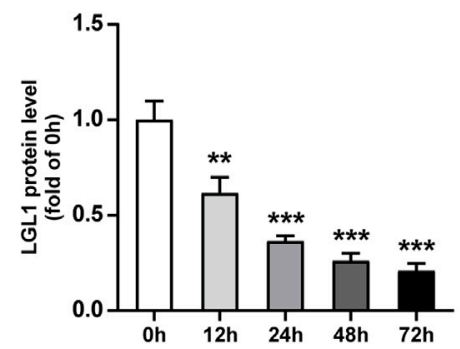

FIGURE 1 | LGL1 expression was decreased during vascular injury in mice. (A,B) Mice underwent left CCA ligation (Ligated) to induce neointimal hyperplasia; the right CCA was a control (Sham). Protein and mRNA levels of carotid artery LGL1 were tested by western blot analysis $(n=4)(\mathbf{A})$ and qRT-PCR $(n=5)$ (B). ${ }^{\star} p<0.05 v s$. Sham. (C) The expression of LGL1 from Sham and Ligated carotid arteries detected by immunohistochemistry $(n=4)$. Scale bar: $50 \mu m$. ${ }^{* \star} p<0.01$ vs. Sham. (D) VSMCs were treated with PDGF-BB (20 ng/ml) for different times, then LGL1 expression was examined by western blot analysis $(n=4)$. ${ }^{\star \star} p<0.01$, ${ }^{\star \star \star} p<0.001$ vs. PDGF-BB $0 \mathrm{~h}$.

and LGL1 deletion promoted cell migration on wound healing assay (Figure 3E). Thus, LGL1 deficiency aggravated the proliferation and migration of VSMCs.

\section{LGL1 Could Bind With STAT3 and Promote its Degradation}

To investigate the molecular mechanism of LGL1 in regulating the proliferation and migration of VSMCs, we analyzed various pathways and related molecules. LGL1 overexpression reduced both STAT3 and P-STAT3 (Y705) protein levels (Figures 4A,B) but not STAT3 mRNA level (Figure 4B). Thus, LGL1 may affect the STAT3 protein level by regulating its degradation. Immunoprecipitation assay revealed that LGL1 could bind with STAT3 (Figure 4C). There are three pathways to promote protein degradation: autophagy, lysosomal, and proteasome pathways. VSMCs were infected with adenovirusexpressing LGL1, then treated with the autophagy inhibitor 3MA, lysosomal inhibitor CQ or proteasome inhibitor MG132 to explore the STAT3 degradation pathway. MG132 but not 3-MA or CQ could reverse the degradation of STAT3 induced by LGL1 overexpression (Figures 4D-F). Taken together, LGL1 could bind with STAT3 and promote its degradation via the proteasomal pathway.

\section{LGL1 Inhibited the Proliferation and Migration of VSMCs via STAT3}

To explore whether LGL1 regulates VSMC proliferation and migration via STAT3, we pretreated control and LGL1-deficient VSMCs with the STAT3 inhibitor SH-4-54 followed by PDGF-BB stimulation. LGL1 deficiency increased the protein and mRNA levels of Cyclin D1 and PCNA, which were attenuated by SH-4-54 (Figures 5A-C). Consistently, LGL1 deletion promoted cell proliferation under PDGF-BB stimulation, which was significantly suppressed by SH-4-54 treatment (Figure 5D). Furthermore, LGL1 deficiency-enhanced cell migration was also attenuated by the STAT3 inhibitor (Figure 5E). Therefore, via STAT3, LGL1 inhibited VSMC proliferation and migration, critical processes in neointimal hyperplasia.

\section{Smooth Muscle-Specific Deletion of LGL1 Promoted Neointimal Hyperplasia via STAT3}

To determine the role of LGL1 in neointimal hyperplasia in vivo, we subjected the control and LGL1 ${ }^{\text {SMKO }}$ mice to vascular injury by carotid ligation for 3 weeks. LGL1 deficiency significantly aggravated neointimal formation, as reflected by enlarged intima area and increased intima/media ratio (Figure 6A). Cyclin D1 and 


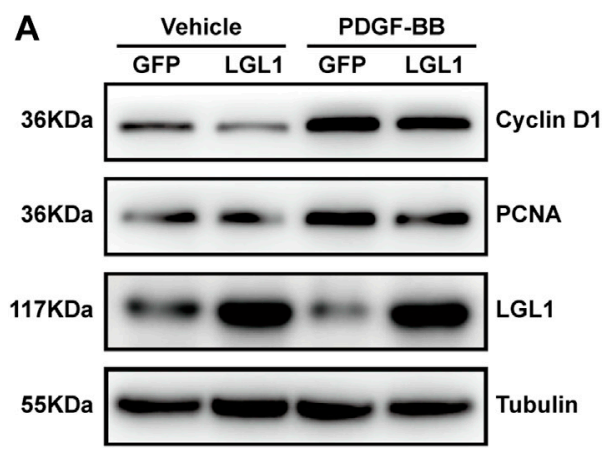

B

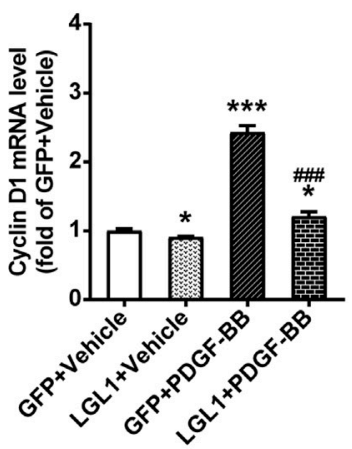

E
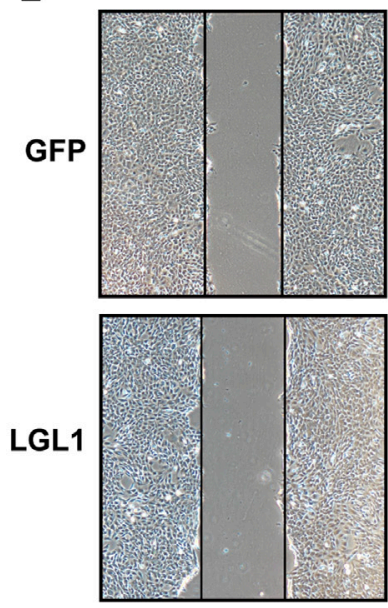

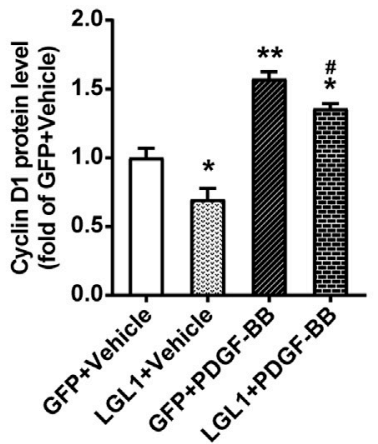

C

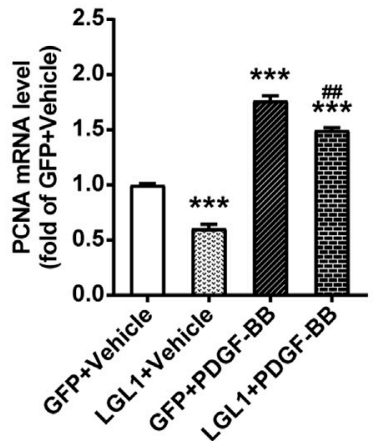

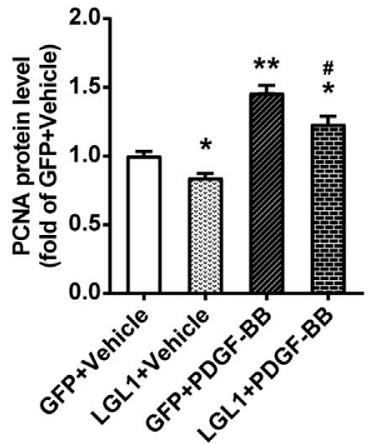

D

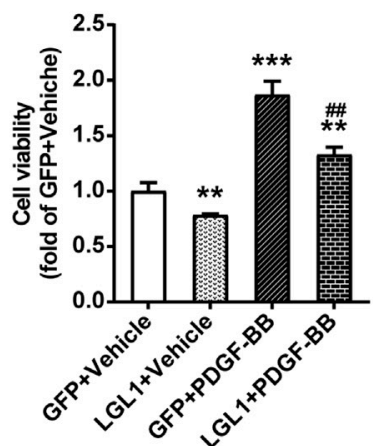

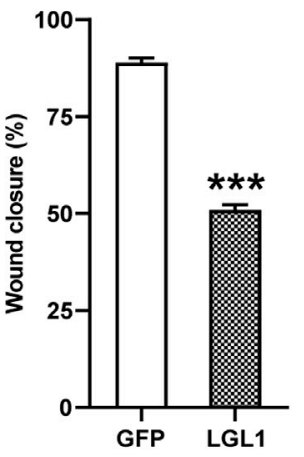

FIGURE 2 | LGL1 overexpression inhibited the proliferation and migration of VSMCs. (A) VSMCs were infected with adenovirus-expressing GFP or LGL1, then treated with PDGF-BB $(20 \mathrm{ng} / \mathrm{ml})$ for $48 \mathrm{~h}$. The protein levels of Cyclin D1 and PCNA were detected by western blot $(n=3) .{ }^{*} p<0.05,{ }^{* *} p<0.01 \mathrm{vs}$. GFP + Vehicle. ${ }^{*} p<$ 0.05 vs. GFP + PDGF-BB. (B, C) The mRNA levels of Cyclin D1 (B) and PCNA (C) were tested by qRT-PCR $(n=4) .{ }^{*} p<0.05,{ }^{* \star *} p<0.001 v s$. GFP + Vehicle. ${ }^{\# \#} p<0.01$, ${ }^{\# \# \# p} p<0.001$ vs. GFP + PDGF-BB. (D) Cell proliferation measured by CCK-8 assay $(n=3) .{ }^{\star *} p<0.01,{ }^{\star \star *} p<0.001$ vs. GFP + Vehicle. ${ }^{\# \#} p<0.01$ vs. GFP + PDGFBB. (E) Cell migration evaluated by scratch wound healing assay $(n=9)$. Wound closure $(\%)$ represented migrative ability. Scale bar: $200 \mu m$. ${ }^{\star \star \star} p<0.001 v s$. GFP.

PCNA levels were increased in LGL1 ${ }^{\mathrm{SMKO}}$ mice, which agreed with the severe neointimal formation (Figures 6B,C). Carotid artery tissues harvested from mice post-surgery showed that ligationinduced upregulation of Cyclin D1 and PCNA was further enhanced by LGL1 deficiency (Figure 6D). Thus, smooth muscle-specific LGL1 knockout promoted neointimal formation.

\section{STAT3 Inhibitor Attenuated Neointimal Hyperplasia in LGL1 ${ }^{\text {SMKO }}$ Mice}

To demonstrate whether LGL1 regulated neointimal hyperplasia via STAT3 in vivo, control and $\mathrm{LGL1}^{\mathrm{SMKO}}$ mice were administrated with STAT3 inhibitor SH-4-54 and then induced to left CCA ligation for 3 weeks. Compared with 


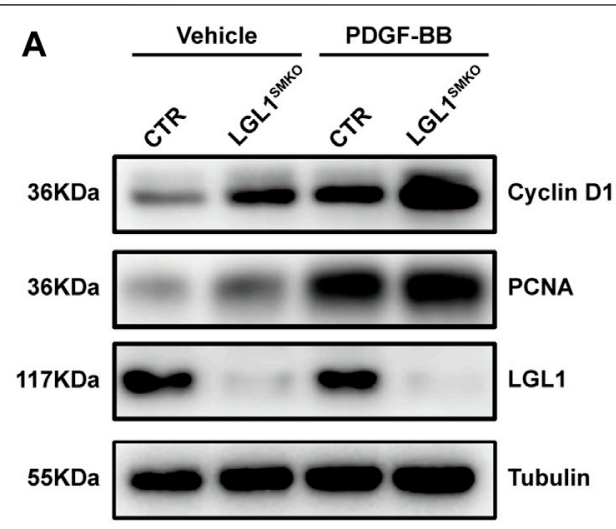

B

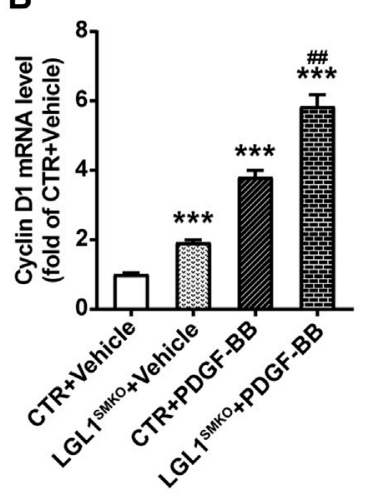

E
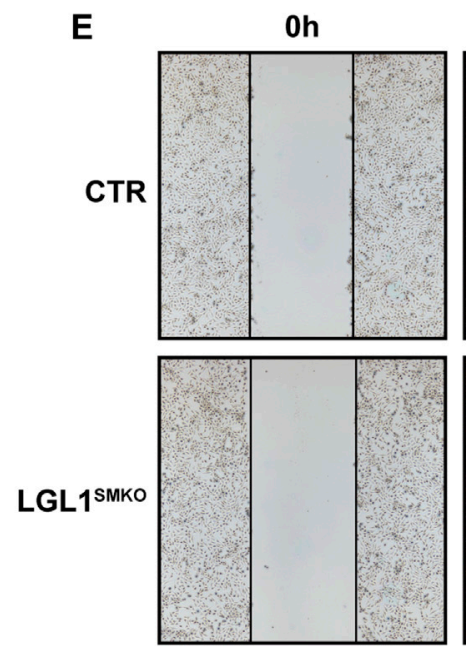

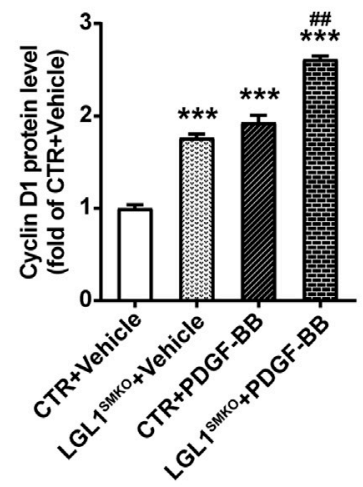

C

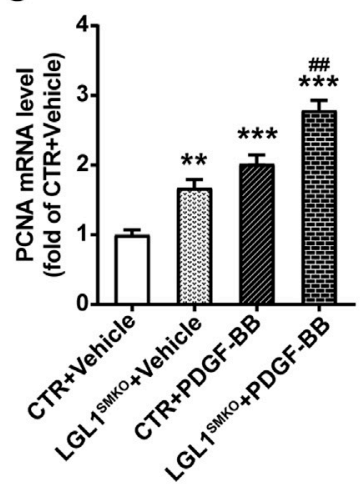

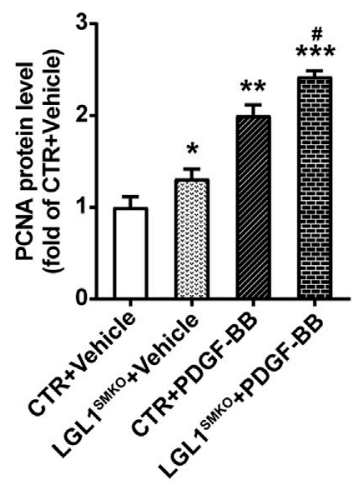

D

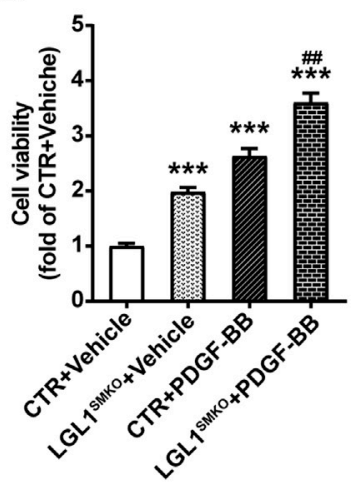

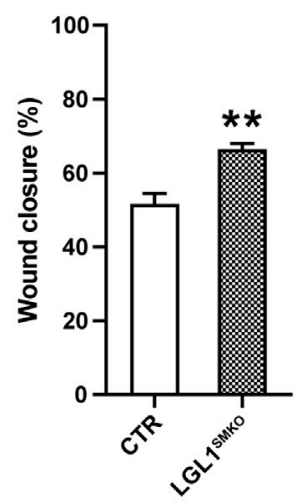

FIGURE 3 | LGL1 deficiency promoted the proliferation and migration of VSMCs. (A) Primary VSMCs were cultured from control (CTR) and LGL1 SMKO mice and treated with PDGF-BB for $48 \mathrm{~h}$. The protein levels of Cyclin D1 and PCNA were detected by western blot analysis $(n=3) .{ }^{*} p<0.05,{ }^{\star \star} p<0.01,{ }^{\star \star \star} p<0.001$ vs. CTR + Vehicle. ${ }^{\#} p<0.05,{ }^{\# \#} p<0.01$ vs. CTR + PDGF-BB. (B,C) mRNA levels of Cyclin D1 (B) and PCNA (C) tested by qRT-PCR $(n=4) .{ }^{* \star} p<0.01,{ }^{* \star *} p<0.001$ vs. CTR + Vehicle. ${ }^{\# \#} p<0.01$ vs. CTR + PDGF-BB. (D) Cell proliferation measured by CCK-8 assay $(n=5) .{ }^{\star \star \star} p<0.001$ vs. CTR + Vehicle. ${ }^{\# \#} p<0.01$ vs. CTR + PDGF-BB. (E) Cell migration evaluated by scratch wound healing assay $(n=4)$. Wound closure (\%) represented migrative ability. Scale bar: $200 \mu \mathrm{m}$. ${ }^{\star \star} p<0.01$ vs. CTR.

control, LGL1 ${ }^{\text {SMKO }}$ mice displayed aggravated neointimal hyperplasia, which was attenuated by $\mathrm{SH}-4-54$ (Figures 7A-C). Taken together, LGL1 regulated the development of neointimal hyperplasia via STAT3 in vivo.

\section{DISCUSSION}

In this study, we found decreased LGL1 expression in both injured carotid arteries and PDGF-BB-induced VSMCs. To 

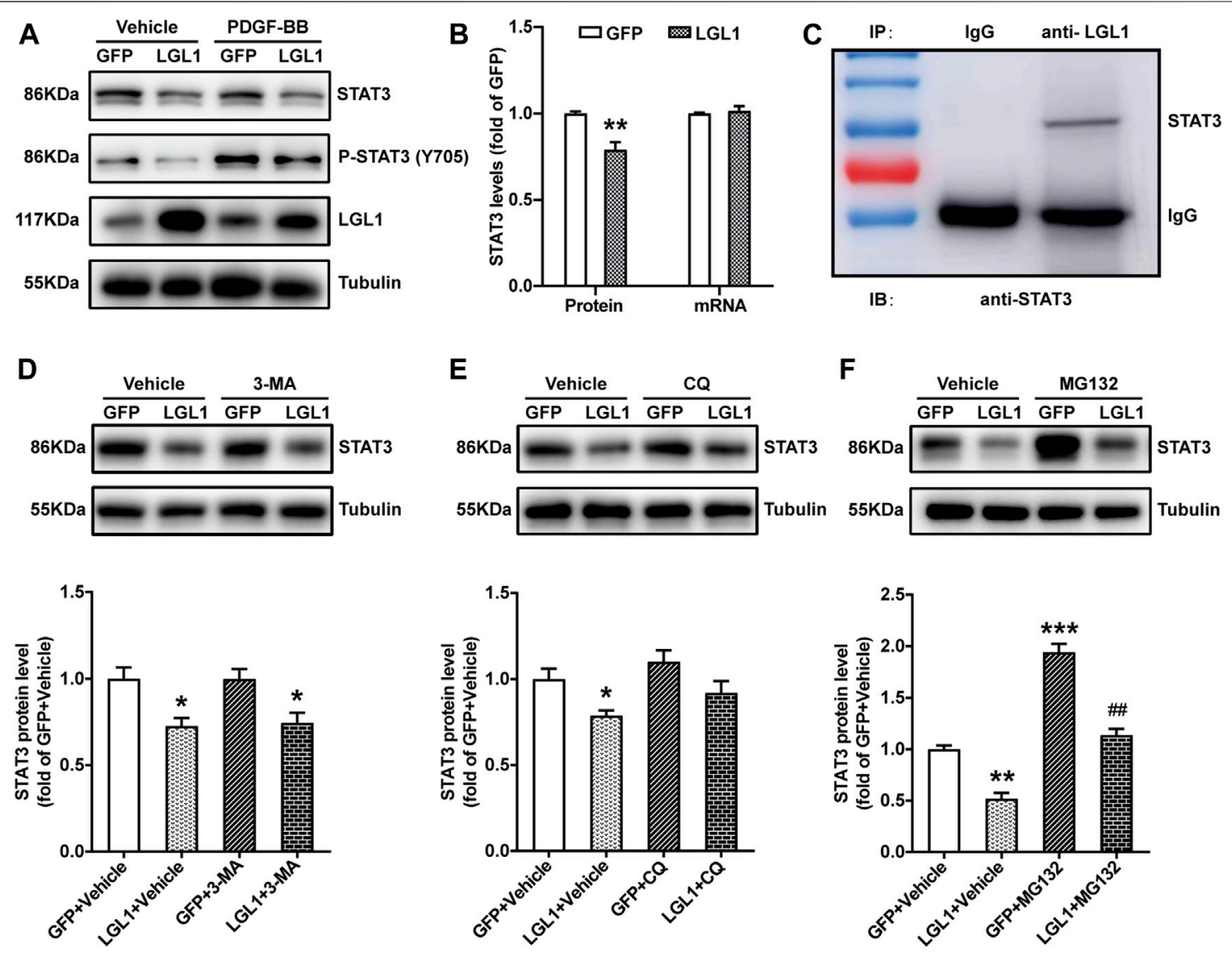

FIGURE 4 | LGL1 could bind with STAT3 and promote its degradation. (A) VSMCs were infected with adenovirus-expressing GFP or LGL1, then treated with PDGF-BB for $15 \mathrm{~min}$. The protein levels of STAT3 and P-STAT3 (Y705) were measured by western blot analysis. (B) Statistical analysis of STAT3 protein and mRNA levels $(n=4)$. ${ }^{* \star} p<0.01$ vs GFP. (C) VSMC lysates were immunoprecipitated with lgG or anti-LGL1 antibody; STAT3 protein level was detected by western blot analysis. (D-F) VSMCs were infected with adenovirus-expressing GFP or LGL1, then treated with $10 \mathrm{mM}$ of the autophagic inhibitor $3-\mathrm{MA}$ for $24 \mathrm{~h}$ (D), $10 \mu \mathrm{M}$ of the lysosomal inhibitor CQ for $24 \mathrm{~h}$ (E) and $1 \mu \mathrm{M}$ of the proteasome inhibitor MG132 for $6 \mathrm{~h}$ (F); STAT3 protein level was detected by western blot analysis $(n=3) .{ }^{*} p<0.05$, ${ }^{* \star} p<0.01,{ }^{\star \star *} p<0.001$ vs. GFP + Vehicle. ${ }^{\# \#} p<0.01$ vs. LGL1 + Vehicle.

investigate the function of LGL1 in neointimal hyperplasia in vivo, we used smooth muscle-specific LGL1-knockout mice: LGL1 deficiency significantly aggravated neointimal formation. LGL1 overexpression inhibited PDGFBB-stimulated proliferation and migration of VSMCs. Mechanistically, LGL1 could bind with STAT3 and promote its degradation via the proteasomal pathway (Figure 7D). Finally, STAT3 inhibitor treatment attenuated neointimal hyperplasia in LGL1 ${ }^{\text {SMKO }}$ mice. Our results reveal that LGL1 inhibited neointimal hyperplasia by promoting STAT3 degradation via the proteasomal pathway.

LGL1, located mainly in the cytoskeleton and plasma membrane (Strand et al., 1995; Kim et al., 2005), has a crucial role in cell polarity, cell division, and differentiation (Betschinger et al., 2003; MartinBelmonte and Perez-Moreno, 2011; Dahan et al., 2012; Zhang et al., 2015). LGL1 alters its biological activity when phosphorylated by atypical protein kinase C (aPKC) (Graybill and Prehoda, 2014). Conjugated with Par/Cdc42/aPKC, LGL1 joins in the complex to regulate cell polarity and membrane development (Plant et al., 2003;
Tocan et al., 2021). In addition, LGL1 in mammals acts as a tumor suppressor in many types of cancer progression (Tsuruga et al., 2007; Lu et al., 2009; Song et al., 2013; Liu et al., 2015). Moreover, LGL1 deficiency in the nervous system caused disrupted asymmetric cell division and lack of differentiation and hyperproliferation to apoptosis in progenitor cells, and mice developed tumors or severe brain dysplasia (Klezovitch et al., 2004; Daynac et al., 2018). Interestingly, the chimeric mice with a hematopoietic system deficient for LGL1 showed a stronger antiviral and antitumor effector $\mathrm{CD}^{+}{ }^{+}$-cell response, which resulted in enhanced control of MC38-OVA tumors (Ramsbottom et al., 2016). Our recent study explored the role of LGL1 in vascular disease. LGL1 inhibited osteogenic differentiation by promoting degradation of high mobility group box protein 1 in vascular calcification (Zhang et al., 2020). In this study, we found that the protein and mRNA levels of LGL1 were decreased in carotid arteries after ligation, which indicates that vascular injury inhibited LGL1 expression at the transcriptional level. Moreover, LGL1 could inhibit neointimal hyperplasia after injury, which amplified the biological function of LGL1. 

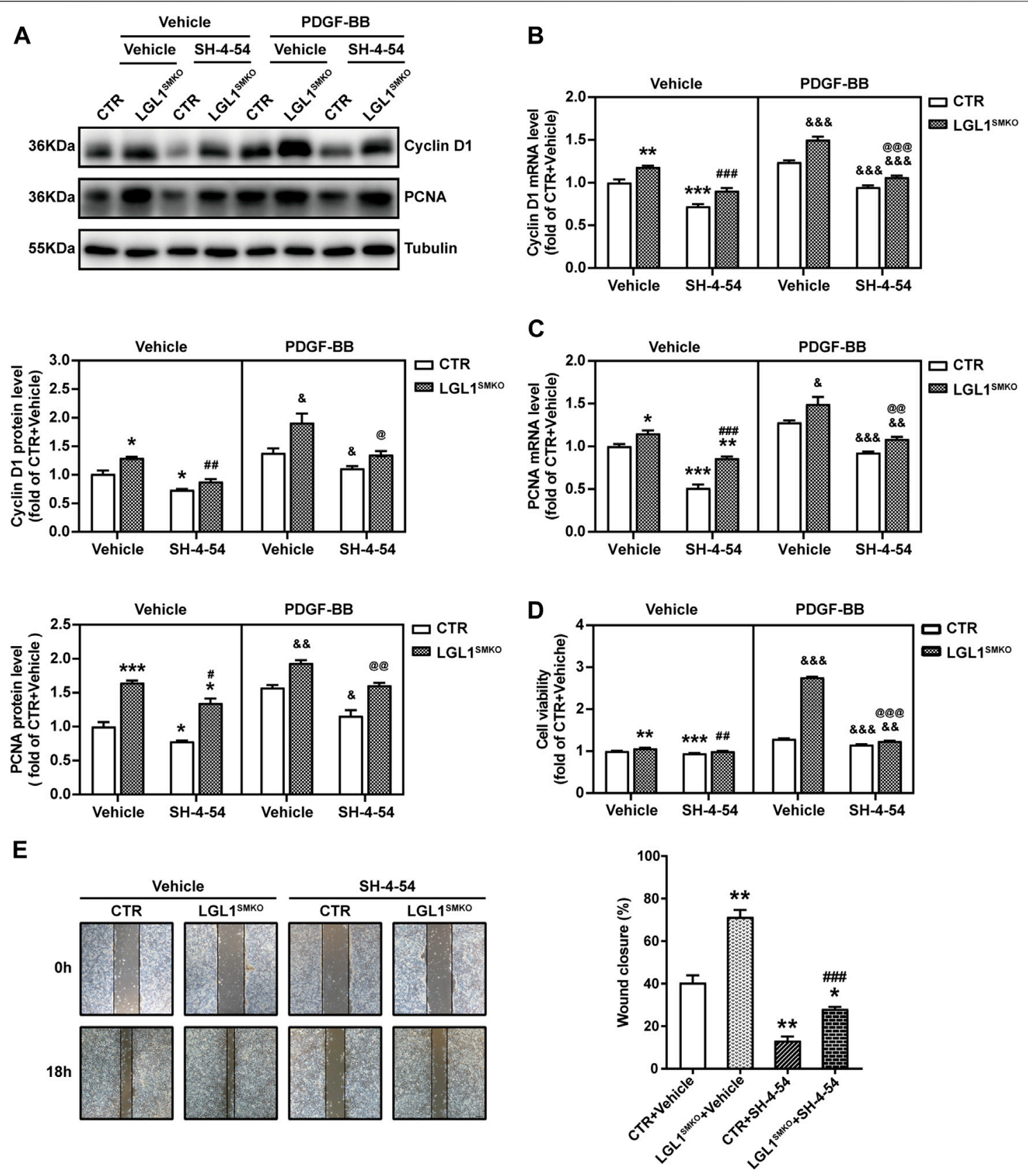

FIGURE 5 | LGL1 inhibited the proliferation and migration of VSMCs via STAT3. (A) Primary VSMCs were cultured from control (CTR) and LGL1 ${ }^{\text {SMKO }}$ mice, pretreated with or without the STAT3 inhibitor SH-4-54 at $10 \mu \mathrm{M}$ for $24 \mathrm{~h}$, and stimulated with PDGF-BB for $48 \mathrm{~h}$. Protein levels of Cyclin D1 and PCNA were detected by western blot analysis $(n=3)$. (B,C) mRNA levels of Cyclin D1 (B) and PCNA (C) tested by qRT-PCR $(n=4)$. (D) Cell proliferation measured by CCK-8 assay $(n=8)$. (E) Cell migration evaluated by the scratch wound healing assay $(n=3)$. Scale bar: $200 \mu \mathrm{m} .{ }^{*} p<0.05,{ }^{* \star} p<0.01,{ }^{\star \star *} p<0.001$ vs. CTR + Vehicle. ${ }^{\#} p<0.05,{ }^{\# \#} p<0.01$, ${ }^{\# \# \#} p<0.001$ vs. LGL1 ${ }^{\text {SMKO }}+$ Vehicle. ${ }^{\&} p<0.05,{ }^{8 \&} p<0.01,{ }^{8 \& \&} p<0.001$ vs. CTR + PDGF-BB. ${ }^{\circledR} p<0.05,{ }^{@ @ ~} p<0.01,{ }^{\circledR @ @ ~} p<0.001$ vs. LGL1 ${ }^{\text {SMKO }}+$ PDGF-BB.

STAT3 plays an important role in many pathological processes. When cells are stimulated by interleukin families, growth factors, angiotensin, erythropoietin, and colony-stimulating factors, tyrosine kinase-associated receptors in the cell membrane transduce the signal to tyrosine kinase (JAK), which phosphorylates STAT3 at Tyr705. Phosphorylated STAT3 dimers translocate into the nucleus to regulate the expression of target genes (Aggarwal et al., 2009; Brooks et al.,
2014). STAT3 phosphorylation at Ser727 could increase the binding stability of DNA with STAT3 and augment its transcriptional activity (Yang et al., 2002). Acetylation at Lys685 was critical for STAT3 dimerization and transcriptional regulation (Yuan et al., 2005). SUMOylation at Lys451 caused the hyperphosphorylation of STAT3 and magnified its transcription activation (Zhou et al., 2016). Also, PIAS3, known as protein inhibitor of activated 

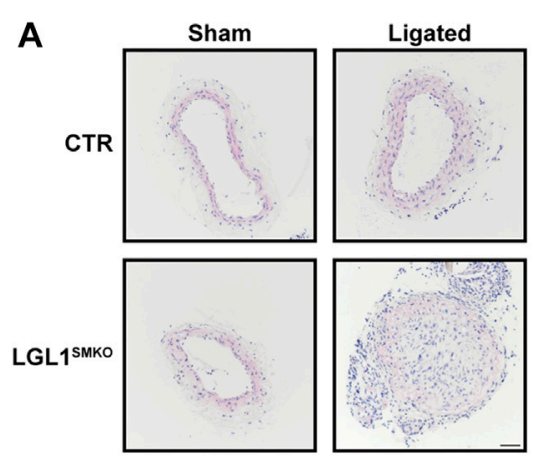

B
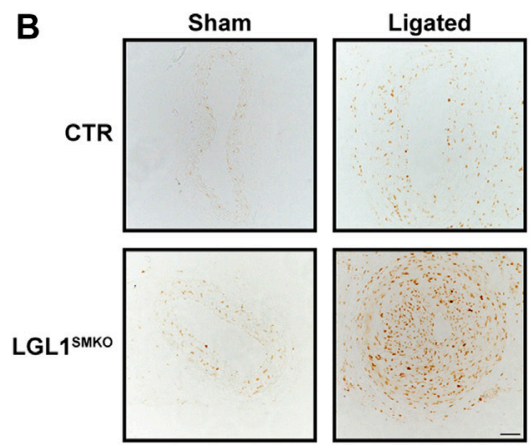

C
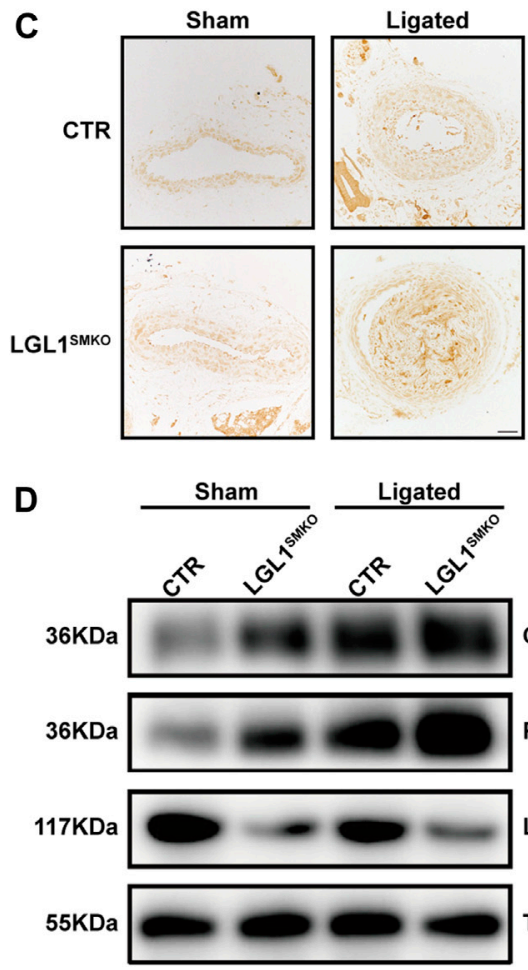

Cyclin D1

PCNA

LGL1

Tubulin
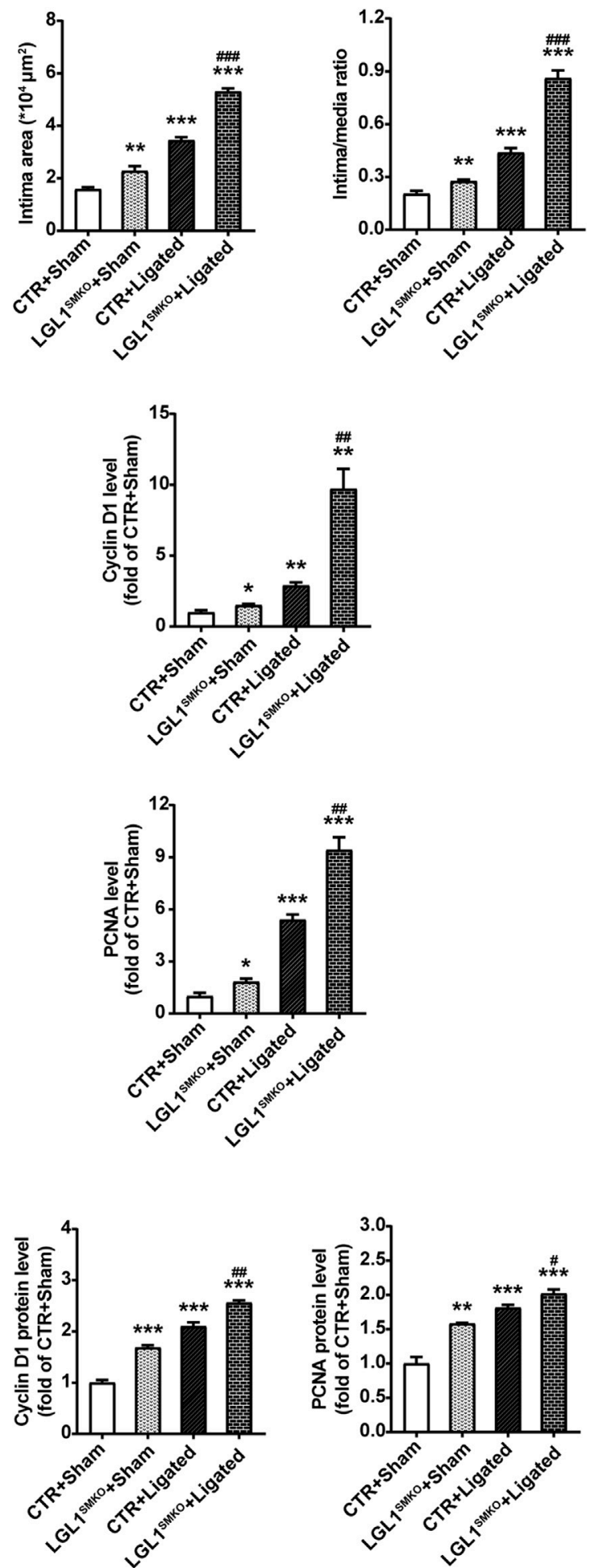

FIGURE 6 | Smooth muscle-specific deletion of LGL1 promoted neointimal hyperplasia via STAT3. (A) Control (CTR) and LGL1 ${ }^{\text {SMKO }}$ mice underwent left CCA ligation (Ligated) to induce neointimal hyperplasia; right CCA was applied as control (Sham). Carotid arteries were stained with HE. The intimal area and intima/media ratio were calculated $(n=6)$. Scale bar: $50 \mu \mathrm{m}$. (B,C) Cyclin D1 (B) and PCNA (C) levels tested by immunohistochemistry $(n=3)$. Scale bar: $50 \mu \mathrm{m}$. (D) Protein levels of Cyclin D1 and PCNA detected by western blot analysis $(n=4) .{ }^{*} p<0.05,{ }^{* *} p<0.01,{ }^{* \star *} p<0.001$ vs. CTR + Sham. ${ }^{\#} p<0.05,{ }^{\# \#} p<0.01,{ }^{\# \# \#} p<0.001$ vs. CTR + Ligated. 
A

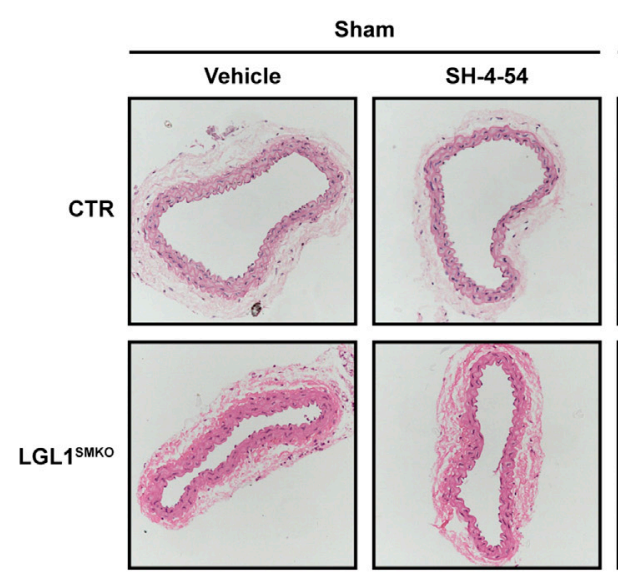

Ligated
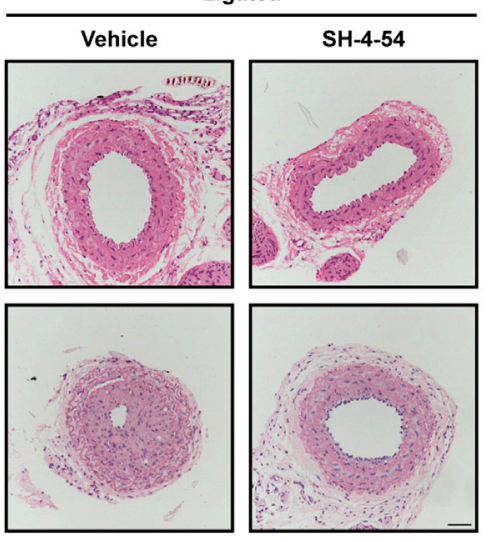

B

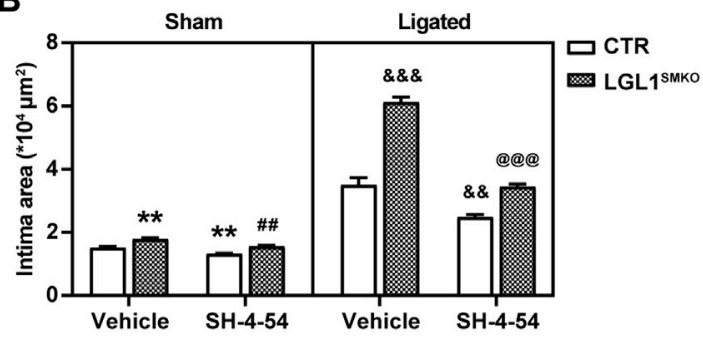

C

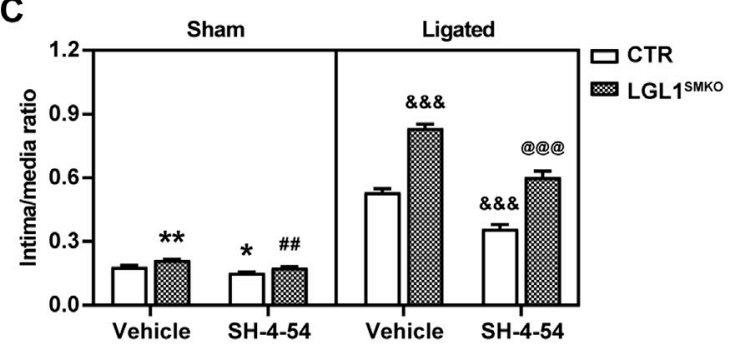

D

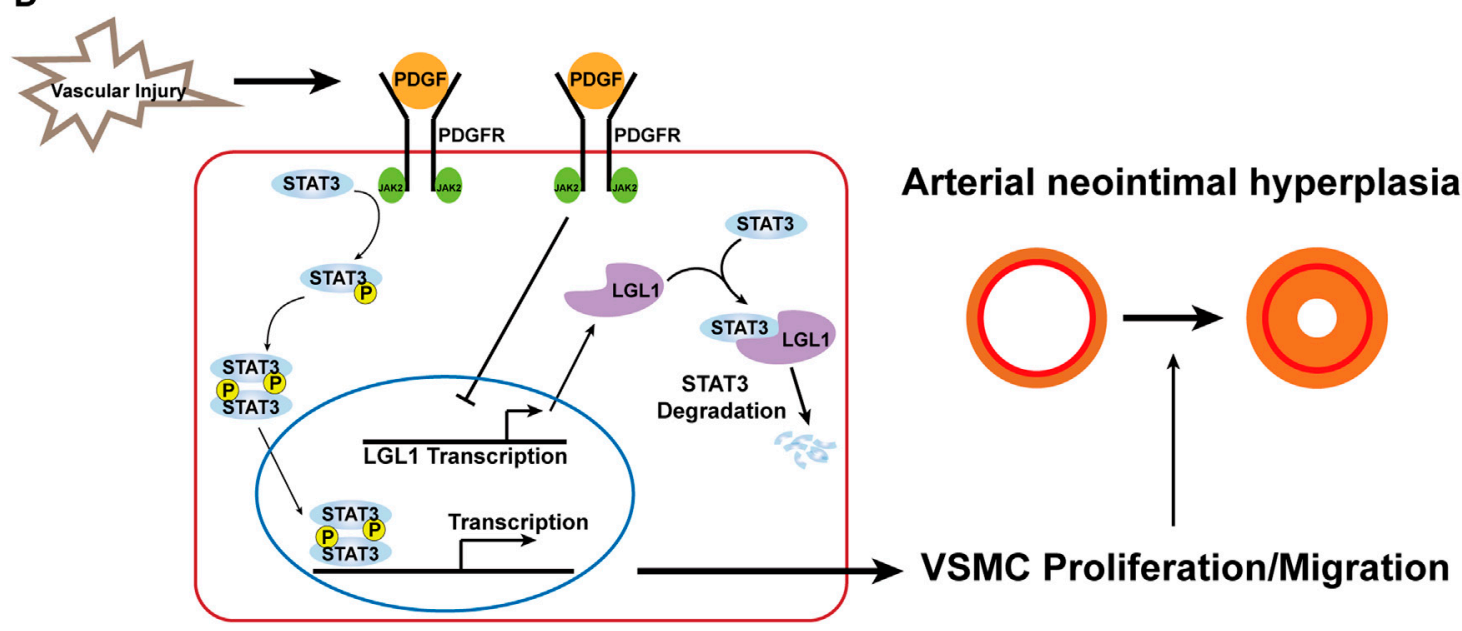

FIGURE 7 |STAT3 inhibitor attenuated neointimal hyperplasia in LGL1 ${ }^{\text {SMKO }}$ mice. (A) CTR and LGL1 ${ }^{\text {SMKO }}$ mice were administrated with STAT3 inhibitor SH-4-54 $(10 \mathrm{mg} / \mathrm{kg})$ daily and then underwent left CCA ligation for 21 days. Carotid arteries were stained with HE. (B,C) The intimal area (B) and intima/media ratio (C) were calculated $(n=4)$. Scale bar: $50 \mu \mathrm{m} .{ }^{*} p<0.05,{ }^{* *} p<0.01$ vs. CTR + Vehicle + Sham. ${ }^{\# \#} p<0.01$ vs. LGL1 ${ }^{\text {SMKO }}+$ Vehicle + Sham. ${ }^{\& \&} p<0.01$, ${ }^{\& \& \&} p<0.001$ vs. CTR + Vehicle + Ligated. ${ }^{@ @} p<0.001$ vs. LGL1 ${ }^{\text {SMKO }}+$ Vehicle + Ligated. (D) Schematic diagram of neointimal hyperplasia inhibition by LGL1 via STAT3 degradation.

STAT3, could block the DNA-binding activity of STAT3 and inhibit STAT3-mediated gene expression (Chung et al., 1997). Moreover, the expression of STAT3 could be modulated by transcription factors such as PPAR $\gamma$, Src and SMAD3, or microRNAs (miRNAs) such as miR-125a-5p and miR-519a (Xiao et al., 2017; Li et al., 2018; Xu et al., 2018; Liu et al., 2021; Zhang et al., 2021). In addition, some small molecules such as SD-36 could degrade STAT3 to disrupt its biological function (Bai et al., 2019; Zhou et al., 2019). In this study, we found that LGL1 could bind with STAT3 and promote its degradation via the proteasomal pathway. In our previous study, we demonstrated that LGL1 could inhibit vascular calcification by preventing osteogenic differentiation through degrading HMGB1 in the lysosomal pathway (Zhang et al., 2020). These results indicated that LGL1 might mediate the degradation of proteins in different 
ways. The detailed mechanisms will be explored in future study. Moreover, the STAT3 inhibitor SH-4-54 attenuated the aggravated neointimal hyperplasia in $\mathrm{LGL1}^{\mathrm{SMKO}}$ mice, which suggests that STAT3 may be a target for preventing and treating vascular diseases.

Neointimal hyperplasia is a complicated process referring to various cells and cellular cytokines. In response to injury, inflammatory cells along with platelets and fibrin recruit immediately around the impaired vascular surface and secrete cytokines such as PDGF-BB, which propel quiescent VSMCs in the tunica media to proliferate and migrate into the intima (Scott, 2006; Kim and Dean, 2011). The dysfunctional endothelium with released active mediators and degraded ECM induce VSMCs to transform from a "contractile" to a "synthetic" phenotype, which is more mobile and productive (Ip et al., 1990; Docherty et al., 1992; Scott, 2006; Park et al., 2020). During the process of neointimal hyperplasia, VSMCs are predominant. Inhibition of the proliferation and migration of VSMCs could be a promising strategy to treat neointima-related diseases such as atherosclerosis. In this study, we demonstrated that LGL1 could inhibit the proliferation and migration of VSMCs, which attenuated neointimal formation and increased our understanding of the mechanism of neointimal hyperplasia. Besides, in our previous study, we demonstrated that LGL1 could inhibit vascular calcification by preventing osteogenic differentiation through degrading HMGB1. These findings disclosed the vital role of LGL1 in vascular remodeling, which suggests that LGL1 may be the potential therapeutic target in the vascular remodeling-related diseases such as atherosclerosis.

In conclusion, we revealed that LGL1 could inhibit neointimal hyperplasia after vascular injury: it suppressed VSMC proliferation and migration by promoting STAT3 degradation via the proteasomal pathway. Our findings may shed light on the mechanism of neointimal formation and provide a novel strategy to treat vascular remodeling diseases.

\section{REFERENCES}

Aggarwal, B. B., Kunnumakkara, A. B., Harikumar, K. B., Gupta, S. R., Tharakan, S. T., Koca, C., et al. (2009). Signal Transducer and Activator of Transcription-3, Inflammation, and Cancer: How Intimate Is the Relationship? Ann. N. Y Acad. Sci. 1171, 59-76. doi:10.1111/j.1749-6632.2009.04911.x

Bai, L., Zhou, H., Xu, R., Zhao, Y., Chinnaswamy, K., McEachern, D., et al. (2019). A Potent and Selective Small-Molecule Degrader of STAT3 Achieves Complete Tumor Regression In Vivo. Cancer Cell 36 (5), 498-511.e17. doi:10.1016/j.ccell. 2019.10.002

Betschinger, J., Mechtler, K., and Knoblich, J. A. (2003). The Par Complex Directs Asymmetric Cell Division by Phosphorylating the Cytoskeletal Protein Lgl. Nature 422 (6929), 326-330. doi:10.1038/nature01486

Bilder, D., Li, M., and Perrimon, N. (2000). Cooperative Regulation of Cell Polarity and Growth by Drosophila Tumor Suppressors. Science 289 (5476), 113-116. doi:10.1126/science.289.5476.113

Brooks, A. J., Dai, W., O’Mara, M. L., Abankwa, D., Chhabra, Y., Pelekanos, R. A., et al. (2014). Mechanism of Activation of Protein Kinase JAK2 by the Growth Hormone Receptor. Science 344 (6185), 1249783. doi:10.1126/science.1249783

Byrne, R. A., Stone, G. W., Ormiston, J., and Kastrati, A. (2017). Coronary Balloon Angioplasty, Stents, and Scaffolds. Lancet 390 (10096), 781-792. doi:10.1016/ S0140-6736(17)31927-X

\section{DATA AVAILABILITY STATEMENT}

The original contributions presented in the study are included in the article/Supplementary Material, further inquiries can be directed to the corresponding authors.

\section{ETHICS STATEMENT}

The animal study was reviewed and approved by the Animal Care and Use Committee of Shandong University.

\section{AUTHOR CONTRIBUTIONS}

YZ and PY designed and performed the research. XM, QD, JG, and JY analyzed data. YZ, TZ, CZ, and WZ conceived the project, reviewed the data, and wrote the manuscript.

\section{FUNDING}

This study was supported by grants from the Natural Science Foundation for Distinguished Young Scholars of Shandong Province (No. ZR2020JQ30), the National Natural Science Foundation of China (No. 81970198 and 81770473), and the Taishan Scholar Project of Shandong Province of China (No. tsqn20161066).

\section{ACKNOWLEDGMENTS}

The authors thank Prof. Valeri Vasioukhin from the Division of Human Biology, Fred Hutchinson Cancer Research Center, for providing the LGL1 ${ }^{\text {flox/flox }}$ mice.

Chung, C. D., Liao, J., Liu, B., Rao, X., Jay, P., Berta, P., et al. (1997). Specific Inhibition of Stat3 Signal Transduction by PIAS3. Science 278 (5344), 1803-1805. doi:10.1126/science.278.5344.1803

Dahan, I., Yearim, A., Touboul, Y., and Ravid, S. (2012). The Tumor Suppressor Lgl1 Regulates NMII-A Cellular Distribution and Focal Adhesion Morphology to Optimize Cell Migration. Mol. Biol. Cel 23 (4), 591-601. doi:10.1091/mbc. E11-01-0015

Daniel, J. M., Dutzmann, J., Bielenberg, W., Widmer-Teske, R., Gündüz, D., Hamm, C. W., et al. (2012). Inhibition of STAT3 Signaling Prevents Vascular Smooth Muscle Cell Proliferation and Neointima Formation. Basic Res. Cardiol. 107 (3), 261. doi:10.1007/s00395-012-0261-9

Daynac, M., Chouchane, M., Collins, H. Y., Murphy, N. E., Andor, N., Niu, J., et al. (2018). Lgl1 Controls NG2 Endocytic Pathway to Regulate Oligodendrocyte Differentiation and Asymmetric Cell Division and Gliomagenesis. Nat. Commun. 9 (1), 2862. doi:10.1038/s41467-018-05099-3

Docherty, A. J., O'Connell, J., Crabbe, T., Angal, S., and Murphy, G. (1992). The Matrix Metalloproteinases and Their Natural Inhibitors: Prospects for Treating Degenerative Tissue Diseases. Trends Biotechnol. 10 (2), 200-207. doi:10.1016/ 0167-7799(92)90214-g

Dutzmann, J., Daniel, J. M., Bauersachs, J., Hilfiker-Kleiner, D., and Sedding, D. G. (2015). Emerging Translational Approaches to Target STAT3 Signalling and its Impact on Vascular Disease. Cardiovasc. Res. 106 (3), 365-374. doi:10.1093/cvr/ cvv103 
Dzau, V. J., Braun-Dullaeus, R. C., and Sedding, D. G. (2002). Vascular Proliferation and Atherosclerosis: New Perspectives and Therapeutic Strategies. Nat. Med. 8 (11), 1249-1256. doi:10.1038/nm1102-1249

Dzau, V. J., Gibbons, G. H., and Pratt, R. E. (1991). Molecular Mechanisms of Vascular Renin-Angiotensin System in Myointimal Hyperplasia. Hypertension 18 (4 Suppl. 1), II100-5. doi:10.1161/01.hyp.18.4_suppl.ii100

Grant, M. B., Wargovich, T. J., Ellis, E. A., Caballero, S., Mansour, M., and Pepine, C. J. (1994). Localization of Insulin-like Growth Factor I and Inhibition of Coronary Smooth Muscle Cell Growth by Somatostatin Analogues in Human Coronary Smooth Muscle Cells. A Potential Treatment for Restenosis? Circulation 89 (4), 1511-1517. doi:10.1161/01.cir.89.4.1511

Graybill, C., and Prehoda, K. E. (2014). Ordered Multisite Phosphorylation of Lethal Giant Larvae by Atypical Protein Kinase C. Biochemistry 53 (30), 4931-4937. doi:10.1021/bi500748w

Grifoni, D., Garoia, F., Schimanski, C. C., Schmitz, G., Laurenti, E., Galle, P. R., et al. (2004). The Human Protein Hugl-1 Substitutes for Drosophila Lethal Giant Larvae Tumour Suppressor Function In Vivo. Oncogene 23 (53), 8688-8694. doi:10.1038/sj.onc.1208023

Harskamp, R. E., Lopes, R. D., Baisden, C. E., de Winter, R. J., and Alexander, J. H. (2013). Saphenous Vein Graft Failure after Coronary Artery Bypass Surgery: Pathophysiology, Management, and Future Directions. Ann. Surg. 257 (5), 824-833. doi:10.1097/SLA.0b013e318288c38d

Ip, J. H., Fuster, V., Badimon, L., Badimon, J., Taubman, M. B., and Chesebro, J. H. (1990). Syndromes of Accelerated Atherosclerosis: Role of Vascular Injury and Smooth Muscle Cell Proliferation. J. Am. Coll. Cardiol. 15 (7), 1667-1687. doi:10.1016/0735-1097(90)92845-s

Kim, M. S., and Dean, L. S. (2011). In-stent Restenosis. Cardiovasc. Ther. 29 (3), 190-198. doi:10.1111/j.1755-5922.2010.00155.x

Kim, Y. K., Kim, Y. S., and Baek, K. H. (2005). The WD-40 Repeat Motif of Lgl Tumor Suppressor Proteins Associated with Salt Tolerance and Temperature Sensitivity. Biochem. Biophys. Res. Commun. 331 (4), 922-928. doi:10.1016/j. bbrc.2005.04.017

Klezovitch, O., Fernandez, T. E., Tapscott, S. J., and Vasioukhin, V. (2004). Loss of Cell Polarity Causes Severe Brain Dysplasia in Lgl1 Knockout Mice. Genes Dev. 18 (5), 559-571. doi:10.1101/gad.1178004

Kuphal, S., Wallner, S., Schimanski, C. C., Bataille, F., Hofer, P., Strand, S., et al. (2006). Expression of Hugl-1 Is Strongly Reduced in Malignant Melanoma. Oncogene 25 (1), 103-110. doi:10.1038/sj.onc.1209008

Li, H., Chen, L., Li, J. J., Zhou, Q., Huang, A., Liu, W. W., et al. (2018). miR-519a Enhances Chemosensitivity and Promotes Autophagy in Glioblastoma by Targeting STAT3/Bcl2 Signaling Pathway. J. Hematol. Oncol. 11 (1), 70. doi:10.1186/s13045-018-0618-0

Lim, S. Y., Kim, Y. S., Ahn, Y., Jeong, M. H., Rok, L. S., Kim, J. H., et al. (2007). The Effects of Granulocyte-colony Stimulating Factor in Bare Stent and SirolimusEluting Stent in Pigs Following Myocardial Infarction. Int. J. Cardiol. 118 (3), 304-311. doi:10.1016/j.ijcard.2006.07.018

Liu, X., Lu, D., Ma, P., Liu, H., Cao, Y., Sang, B., et al. (2015). Hugl-1 Inhibits Glioma Cell Growth in Intracranial Model. J. Neurooncol. 125 (1), 113-121. doi:10.1007/s11060-015-1901-3

Liu, Z., Meng, Y., Miao, Y., Yu, L., Wei, Q., Li, Y., et al. (2021). Propofol Ameliorates Renal Ischemia/reperfusion Injury by Enhancing Macrophage M2 Polarization through PPAR $\gamma /$ STAT3 Signaling. Aging (Albany NY) 13 (11), 15511-15522. doi:10.18632/aging.203107

Lu, X., Feng, X., Man, X., Yang, G., Tang, L., Du, D., et al. (2009). Aberrant Splicing of Hugl-1 Is Associated with Hepatocellular Carcinoma Progression. Clin. Cancer Res. 15 (10), 3287-3296. doi:10.1158/10780432.CCR-08-2078

Majesky, M. W., Lindner, V., Twardzik, D. R., Schwartz, S. M., and Reidy, M. A. (1991). Production of Transforming Growth Factor Beta 1 during Repair of Arterial Injury. J. Clin. Invest. 88 (3), 904-910. doi:10.1172/JCI115393

Martin-Belmonte, F., and Perez-Moreno, M. (2011). Epithelial Cell Polarity, Stem Cells and Cancer. Nat. Rev. Cancer 12 (1), 23-38. doi:10.1038/nrc3169

Nabel, E. G., Yang, Z., Liptay, S., San, H., Gordon, D., Haudenschild, C. C., et al. (1993). Recombinant Platelet-Derived Growth Factor B Gene Expression in Porcine Arteries Induce Intimal Hyperplasia In Vivo. J. Clin. Invest. 91 (4), 1822-1829. doi:10.1172/JCI116394

Park, K. S., Kang, S. N., Kim, D. H., Kim, H. B., Im, K. S., Park, W., et al. (2020). Late Endothelial Progenitor Cell-Capture Stents with CD146 Antibody and
Nanostructure Reduce In-Stent Restenosis and Thrombosis. Acta Biomater. 111, 91-101. doi:10.1016/j.actbio.2020.05.011

Park, O. K., Schaefer, L. K., Wang, W., and Schaefer, T. S. (2000). Dimer Stability as a Determinant of Differential DNA Binding Activity of Stat3 Isoforms. J. Biol. Chem. 275 (41), 32244-32249. doi:10.1074/jbc.M005082200

Plant, P. J., Fawcett, J. P., Lin, D. C., Holdorf, A. D., Binns, K., Kulkarni, S., et al. (2003). A Polarity Complex of mPar-6 and Atypical PKC Binds, Phosphorylates and Regulates Mammalian Lgl. Nat. Cel Biol 5 (4), 301-308. doi:10.1038/ncb948

Ramsbottom, K. M., Sacirbegovic, F., Hawkins, E. D., Kallies, A., Belz, G. T., Van Ham, V., et al. (2016). Lethal Giant Larvae-1 Deficiency Enhances the CD8(+) Effector T-Cell Response to Antigen challenge In Vivo. Immunol. Cel Biol 94 (3), 306-311. doi:10.1038/icb.2015.82

Roy-Chaudhury, P., Arend, L., Zhang, J., Krishnamoorthy, M., Wang, Y., Banerjee, R., et al. (2007). Neointimal Hyperplasia in Early Arteriovenous Fistula Failure. Am. J. Kidney Dis. 50 (5), 782-790. doi:10.1053/j.ajkd.2007.07.019

Roy-Chaudhury, P., Kelly, B. S., Miller, M. A., Reaves, A., Armstrong, J., Nanayakkara, N., et al. (2001). Venous Neointimal Hyperplasia in Polytetrafluoroethylene Dialysis Grafts. Kidney Int. 59 (6), 2325-2334. doi:10.1046/j.1523-1755.2001.00750.x

Russ, A., Louderbough, J. M., Zarnescu, D., and Schroeder, J. A. (2012). Hugl1 and Hugl2 in Mammary Epithelial Cells: Polarity, Proliferation, and Differentiation. PLoS One 7 (10), e47734. doi:10.1371/journal.pone.0047734

Schwartz, S. M., deBlois, D., and O'Brien, E. R. (1995). The Intima. Soil for Atherosclerosis and Restenosis. Circ. Res. 77 (3), 445-465. doi:10.1161/01.res. 77.3.445

Scott, N. A. (2006). Restenosis Following Implantation of Bare Metal Coronary Stents: Pathophysiology and Pathways Involved in the Vascular Response to Injury. Adv. Drug Deliv. Rev. 58 (3), 358-376. doi:10.1016/j.addr.2006.01.015

Shibata, R., Kai, H., Seki, Y., Kato, S., Wada, Y., Hanakawa, Y., et al. (2003). Inhibition of STAT3 Prevents Neointima Formation by Inhibiting Proliferation and Promoting Apoptosis of Neointimal Smooth Muscle Cells. Hum. Gene Ther. 14 (7), 601-610. doi:10.1089/104303403321618128

Song, J., Peng, X. L., Ji, M. Y., Ai, M. H., Zhang, J. X., and Dong, W. G. (2013). Hugl-1 Induces Apoptosis in Esophageal Carcinoma Cells Both In Vitro and In Vivo. World J. Gastroenterol. 19 (26), 4127-4136. doi:10.3748/wjg. v19.i26.4127

Strand, D., Unger, S., Corvi, R., Hartenstein, K., Schenkel, H., Kalmes, A., et al. (1995). A Human Homologue of the Drosophila Tumour Suppressor Gene L(2) gl Maps to 17p11.2-12 and Codes for a Cytoskeletal Protein that Associates with Nonmuscle Myosin II Heavy Chain. Oncogene 11 (2), 291-301.

Sun, J., Zheng, J., Ling, K. H., Zhao, K., Xie, Z., Li, B., et al. (2012). Preventing Intimal Thickening of Vein Grafts in Vein Artery Bypass Using STAT-3 siRNA. J. Transl Med. 10, 2. doi:10.1186/1479-5876-10-2

Tian, A. G., and Deng, W. M. (2008). Lgl and its Phosphorylation by aPKC Regulate Oocyte Polarity Formation in Drosophila. Development 135 (3), 463-471. doi:10.1242/dev.016253

Tocan, V., Hayase, J., Kamakura, S., Kohda, A., Ohga, S., Kohjima, M., et al. (2021). Hepatocyte Polarity Establishment and Apical Lumen Formation Are Organized by Par3, Cdc42, and aPKC in Conjunction with Lgl. J. Biol. Chem. 297, 101354. doi:10.1016/j.jbc.2021.101354

Tsuruga, T., Nakagawa, S., Watanabe, M., Takizawa, S., Matsumoto, Y., Nagasaka, K., et al. (2007). Loss of Hugl-1 Expression Associates with Lymph Node Metastasis in Endometrial Cancer. Oncol. Res. 16 (9), 431-435. doi:10.3727/ 000000007783980855

Wang, D., Liu, Z., Li, Q., Karpurapu, M., Kundumani-Sridharan, V., Cao, H., et al. (2007). An Essential Role for Gp130 in Neointima Formation Following Arterial Injury. Circ. Res. 100 (6), 807-816. doi:10.1161/01.RES.0000261350. $61711.9 \mathrm{e}$

Wu, W., Zhang, W., Choi, M., Zhao, J., Gao, P., Xue, M., et al. (2019). Vascular Smooth Muscle-MAPK14 Is Required for Neointimal Hyperplasia by Suppressing VSMC Differentiation and Inducing Proliferation and Inflammation. Redox Biol. 22, 101137. doi:10.1016/j.redox.2019.101137

Wu, Z., Yang, L., Cai, L., Zhang, M., Cheng, X., Yang, X., et al. (2007). Detection of Epithelial to Mesenchymal Transition in Airways of a Bleomycin Induced Pulmonary Fibrosis Model Derived from an Alpha-Smooth Muscle Actin-Cre Transgenic Mouse. Respir. Res. 8 (1), 1. doi:10.1186/1465-9921-8-1 
Xiao, X., Fischbach, S., Zhang, T., Chen, C., Sheng, Q., Zimmerman, R., et al. (2017). SMAD3/Stat3 Signaling Mediates $\beta$-Cell Epithelial-Mesenchymal Transition in Chronic Pancreatitis-Related Diabetes. Diabetes 66 (10), 2646-2658. doi:10.2337/db17-0537

Xu, L., Li, Y., Yin, L., Qi, Y., Sun, H., Sun, P., et al. (2018). miR-125a-5p Ameliorates Hepatic Glycolipid Metabolism Disorder in Type 2 Diabetes Mellitus through Targeting of STAT3. Theranostics 8 (20), 5593-5609. doi:10. 7150/thno.27425

Yang, E., Henriksen, M. A., Schaefer, O., Zakharova, N., and Darnell, J. E., Jr. (2002). Dissociation Time from DNA Determines Transcriptional Function in a STAT1 Linker Mutant. J. Biol. Chem. 277 (16), 13455-13462. doi:10.1074/jbc. M112038200

Yuan, Z. L., Guan, Y. J., Chatterjee, D., and Chin, Y. E. (2005). Stat3 Dimerization Regulated by Reversible Acetylation of a Single Lysine Residue. Science 307 (5707), 269-273. doi:10.1126/science.1105166

Zaman, A. G., and Herath, J. (2008). "Percutaneous Coronary Intervention in Saphenous Vein Graft Disease," in Essential Interventional Cardiology. Editors M. S. Norell, J. Perrins, B. Meier, and A. M. Lincoff. Second Edition (Philadelphia: W.B. Saunders), 309-318.

Zhang, H., Sweezey, N. B., and Kaplan, F. (2015). LGL1 Modulates Proliferation, Apoptosis, and Migration of Human Fetal Lung Fibroblasts. Am. J. Physiol. Lung Cel Mol Physiol 308 (4), L391-L402. doi:10.1152/ajplung.00119.2014

Zhang, T., Cao, G., Meng, X., Ouyang, C., Gao, J., Sun, Y., et al. (2020). Lethal Giant Larvae 1 Inhibits Smooth Muscle Calcification via High Mobility Group Box 1. J. Mol. Cel Cardiol 142, 39-52. doi:10.1016/j.yjmcc.2020.03.017

Zhang, X., Xu, H., Bi, X., Hou, G., Liu, A., Zhao, Y., et al. (2021). Src Acts as the Target of Matrine to Inhibit the Proliferation of Cancer Cells by Regulating
Phosphorylation Signaling Pathways. Cell Death Dis 12 (10), 931. doi:10.1038/ s41419-021-04221-6

Zhou, H., Bai, L., Xu, R., Zhao, Y., Chen, J., McEachern, D., et al. (2019). StructureBased Discovery of SD-36 as a Potent, Selective, and Efficacious PROTAC Degrader of STAT3 Protein. J. Med. Chem. 62 (24), 11280-11300. doi:10.1021/ acs.jmedchem.9b01530

Zhou, Z., Wang, M., Li, J., Xiao, M., Chin, Y. E., Cheng, J., et al. (2016). SUMOylation and SENP3 Regulate STAT3 Activation in Head and Neck Cancer. Oncogene 35 (45), 5826-5838. doi:10.1038/onc.2016.124

Conflict of Interest: The authors declare that the research was conducted in the absence of any commercial or financial relationships that could be construed as a potential conflict of interest.

Publisher's Note: All claims expressed in this article are solely those of the authors and do not necessarily represent those of their affiliated organizations, or those of the publisher, the editors and the reviewers. Any product that may be evaluated in this article, or claim that may be made by its manufacturer, is not guaranteed or endorsed by the publisher.

Copyright (c) 2022 Zhang, Yuan, Ma, Deng, Gao, Yang, Zhang, Zhang and Zhang. This is an open-access article distributed under the terms of the Creative Commons Attribution License (CC BY). The use, distribution or reproduction in other forums is permitted, provided the original author(s) and the copyright owner(s) are credited and that the original publication in this journal is cited, in accordance with accepted academic practice. No use, distribution or reproduction is permitted which does not comply with these terms. 